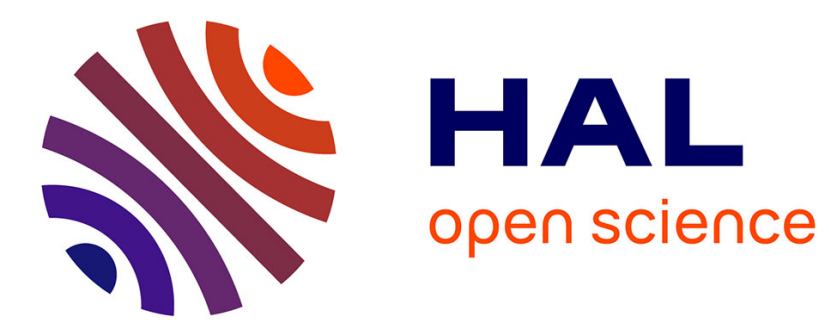

\title{
Observing ice clouds with a Doppler cloud radar
}

Artemio Plana-Fattori, Alain Protat, Julien Delanoë

\section{To cite this version:}

Artemio Plana-Fattori, Alain Protat, Julien Delanoë. Observing ice clouds with a Doppler cloud radar.

Comptes Rendus. Physique, 2010, 11 (1), pp.96-103. 10.1016/j.crhy.2009.11.004 . hal-00463623

\section{HAL Id: hal-00463623 \\ https://hal.science/hal-00463623}

Submitted on 1 Feb 2021

HAL is a multi-disciplinary open access archive for the deposit and dissemination of scientific research documents, whether they are published or not. The documents may come from teaching and research institutions in France or abroad, or from public or private research centers.
L'archive ouverte pluridisciplinaire HAL, est destinée au dépôt et à la diffusion de documents scientifiques de niveau recherche, publiés ou non, émanant des établissements d'enseignement et de recherche français ou étrangers, des laboratoires publics ou privés. 
Observing Ice Clouds with a Doppler Cloud Radar

\title{
Observation de Nuages de Glace avec un Radar Nuage Doppler
}

Artemio Plana-Fattori (a), Alain Protat (a b *), and Julien Delanoë (c)

(a) Université de Versailles St. Quentin en Yvelines, CNRS / INSU,

Laboratoire Atmosphères Milieux, Observations Spatiales (LATMOS) / IPSL, 10-12 avenue de l'Europe, 78140 Vélizy, France

(b) Centre for Australian Weather and Climate Research (CAWCR) -

700 Collins Street, Docklands, VIC3008 Melbourne, Australia

(c) Department of Meteorology, University of Reading -

Earley Gate, PO box 243, Reading RG6 6BB, United Kingdom

\begin{abstract}
Cloud systems containing ice particles ("ice clouds") must be realistically represented in numerical models devoted to weather forecasting and climate projection. Nevertheless, such clouds have not been fully characterized. The RadOn method (after Radar Only) has been developed for estimating microphysical properties of ice clouds from Doppler cloud radar observations. This method is here updated and applied to observations conducted in 2003-2004 with the Doppler cloud radar RASTA at the SIRTA observatory (Palaiseau, near Paris).
\end{abstract}

Résumé - Les systèmes nuageux contenant de particules de glace ("nuages de glace") doivent être représentés de façon réaliste au sein des modèles consacrés à la prévision du temps et à la simulation du climat. Néanmoins, ces nuages ne sont pas suffisamment connus. Cet article présente l'état actuel de la méthode RadOn, conçue pour estimer les propriétés microphysiques des nuages de glace à partir d'observations effectuées à l'aide d'un radar nuage Doppler. L'application de cette méthode aux observations acquises en 2003 et 2004 à l'aide de l'instrument RASTA à l'observatoire SIRTA (Palaiseau) est ici analysée en détail.

Keywords: Climate; Meteorology; Clouds; Ice particles; Doppler radar

Mots-clés: Climat; Météorologie; Nuages; Particules de glace; Radar Doppler

(*) Corresponding author. CNRS, INSU and IPSL mean Centre National de la Recherche Scientifique, Institut National des Sciences de l'Univers, and Institut Pierre Simon Laplace, respectively. E-mail addresses: artemio.planafattori@latmos.ipsl.fr, a.protat@bom.gov.au,j.m.e.delanoe@reading.ac.uk .

\section{Introduction}

Clouds play an important role in the processes which determine air and surface temperatures that occur in our habitat. Daytime warming is reduced by clouds, because they reflect back to space a fraction of incident sunlight which could be absorbed by the ground and selected atmospheric constituents. Ground cooling by infrared emission is slowed down by clouds, because they increase radiative exchange between the ground and atmospheric layers. Moreover, the own cloud life cycle is associated with energy exchanges (evaporation, condensation, precipitation...). In order to represent clouds and cloud-radiation interactions as accurately as possible, large-scale models employed in forecasting weather and projecting climate apply a number of assumptions regarding cloud macroscopic- (e.g. height and thickness) and microscopic properties (particles' concentration, size, shape). The optimization of such assumptions requires a better understanding of the statistical characteristics of clouds as well as the variability of these characteristics as a function of different temporal and spatial scales, or physical parameters describing the large-scale environment. Stephens et al. [1] discuss the subject from the perspective of space-borne observations. 
The observation of cloud microphysical properties is challenging: a) they vary meaningfully in time and space; b) their in-situ sampling with airborne instrumentation is expensive and limited in time and space; and c) their remote monitoring can be incomplete because each instrument (optical or microwave, passive or active) is able to detect distinct cloud elements. The achievement of such a goal is particularly difficult in the case of clouds containing ice particles (hereafter ice clouds). The measured ranges displayed by the various properties - thickness, height, particle concentration and dimension - show that ice clouds defy comfortable characterization by any single set of numbers [2]. Thin ice clouds, associated with visible optical thickness smaller than three, have been monitored with the help of ground-based lidar instrumentation [3-5]. Thicker ice clouds are accessible through radar instrumentation at selected microwave transmission windows for water vapor and molecular oxygen [6], and different types of ice particles present in a radar observation volume can be discriminate using spectral polarimetry [7]. Cloud elements detected simultaneously by radar and lidar have been studied [8], as well as those detected simultaneously by radar and microwave radiometer [9]. The analysis of all the cloud elements detected at least by one among radar, lidar, and radiometer allows a better picture of the cloud cover [10]. The simplest strategy involves datasets obtained with one instrument only: the latter is at the origin of all the interruptions during the dataset constitution, and field experience has shown that the resulting time series of measurements is denser than after operating two or more instruments as longer as possible.

The RadOn method (after Radar Only) has been developed at the former Centre d'Etude des Environnements Terrestre et Planétaires (CETP) with the aim of estimating microphysical properties of ice clouds observed with the help of a vertically-looking Doppler cloud radar [11-13]. The method is applied to observations of radar reflectivity (Ze) and Doppler velocity (Vd) which have been previously time- and height- averaged (e.g. 30 seconds and 60 meters). Doppler velocities under consideration result from the air vertical motion $(\mathrm{Vw})$ and the particles' fall speed (hereafter terminal velocity, Vt). The latter has been characterized in connection with ice particle microphysics [14-15]. The application of the method requires a long sampling time span (a day for ground-based observations, or an aircraft mission), after which the mean vertical air motions could vanish with respect to the mean terminal velocity. Ice microphysical properties are estimated for a particle model (size distribution and shape) which is previously identified as being the most probable one, after comparisons between the experimental Vt-Ze relationship and its theoretical counterparts.

Looking for more realistic retrievals of the vertical structure of microphysical properties of ice clouds obtained with the RadOn method, this article proposes a higher order approximation between ice particle terminal velocity and radar reflectivity, by including the height $(\mathrm{H})$. Sections 2 and 3 present the method and the dataset under consideration, respectively. Ice cloud properties estimated with the help of the Vt-Ze and Vt-Ze-H approaches are compared in Section 4. Summary and perspectives are given in Section 5.

\section{Method}

The application of the RadOn method provides a number of ice cloud properties at the same time and height resolution at which Doppler velocity and radar reflectivity are available. Main results include the air vertical velocity and selected ice particle microphysical properties (terminal velocity, number and mass concentration), and also two bulk ice particle optical properties (effective radius and visible extinction coefficient) which are used in radiative transfer codes of large-scale models.

The RadOn method is based upon:

- a normalized ice particle size distribution (PSD), which is expressed in terms of the equivalent melted diameter (= diameter the ice particle would have if it was a spherical water particle of the same mass);

- an extensive airborne in-situ microphysics dataset including different types of ice clouds at different latitudes, from which two theoretical libraries were built: the first links terminal 
velocity and radar reflectivity through a number of ice particle models associated with selected habits (hexagonal columns, aggregates, etc), and the second links ice particle properties and radar reflectivity through the same particle models;

- the search of the most probable ice particle model after comparing the experimental Vt-Ze relationship with those contained in the first library; and

- the estimation of the microphysical properties which correspond to the most probable particle model in the second library, for each radar reflectivity observation.

Further details about RadOn have been provided elsewhere [11-13]. Both libraries based upon the insitu microphysics dataset were updated in respect to their early version. Present libraries are more accurate regarding the influence of large ice particles on the computation of the radar reflectivity and of microphysical and optical properties. On the other hand, the early implementation of the method employed the relationship $\mathrm{Vt}=-\mathrm{A} 1 \mathrm{Ze}^{\mathrm{B} 1}$ for estimating the terminal velocity, where $\mathrm{A} 1$ and $\mathrm{B} 1$ are parameters to be estimated from Doppler velocity and radar reflectivity observations.

The present RadOn implementation includes a major improvement. Alternatively to the Vt-Ze approach, we propose the inclusion of the height $\mathrm{H}$ (either from the cloud base or from the ground surface) as independent variable:

$$
\mathrm{Vt}=-\left(\mathrm{A} 11 \mathrm{H}^{\mathrm{A} 12}\right) \mathrm{Ze} \mathrm{(B11+H} \mathrm{B12)}^{(.}
$$

Such a higher-order approximation can be justified by the fact that the apparent density of ice particles (= density of a hypothetical sphere which contains the ice particle and surrounding air) is known to vary a lot with height in a given cloud owing to the different microphysical processes. Additional freedom is hence allowed in associating terminal velocity and radar reflectivity. Parameters required in the Vt-Ze (the Vt-Ze-H) approach are estimated through weighted least-square fitting from Doppler velocity and radar reflectivity observations (and height associated with observations) which were averaged over a number of reflectivity (and height) bins.

\section{Observations}

The Doppler cloud radar at $95 \mathrm{GHz}$ named RASTA (standing for Radar Áéroporté et $\underline{\text { Sol de }}$ Télédétection des propriétés nuAgeuses) was entirely conceived at the former CETP in the scope of the RALI (after RAdar-LIdar) project, which combines a millimeter radar and a dual polarization backscatter lidar for observing weakly-precipitating clouds [16].

Ground-based observations performed with the help of RASTA in its one-antenna zenithlooking configuration between January 2003 and September 2004 at the SIRTA observatory located in Palaiseau near Paris [3] are here analyzed. In the framework of the European project CloudNet [17], an extended instrument deployment was reached at SIRTA during that period, including a backscatter lidar and a microwave radiometer. For that project, a data product designed to facilitate the application of multi-sensor algorithms by performing most of the typical preprocessing that such algorithms require and providing the results in a common format was developed [18]. In such a data product, observations were associated with the occurrence of solid hydrometeors ever than the wet-bulb air temperature value was lower than $0^{\circ} \mathrm{C}$. It was the case of more than $13.7 \mathrm{E}+6$ RASTA observations averaged over 30 seconds and 60 meters (one radar bin) distributed in 289 daily datasets in 2003-2004. As an additional criterion, we have discarded roughly 9.1E+6 RASTA observations which were affected by attenuation (caused by liquid water cloud or rainfall below the radar bin under consideration) whose effects were not properly corrected.

It must be stressed that a number of factors can forbid the application of RadOn. We have excluded daily datasets associated with a too narrow reflectivity range (less than $20 \mathrm{dBZ}$ ) or with reflectivity-averaged values for the Doppler velocity indicating upward motion. Finally, 3.9E +6 RASTA observations distributed in 166 daily datasets were retained for further analysis. 


\section{Results}

Displays A and B in Figure 1 present radar reflectivity and Doppler velocity observations, from the dataset obtained with the help of the Doppler cloud radar RASTA on 14 April 2003. Reflectivity values are lower in the upper part of the cloud cover (where particles are typically smaller) as well as its boundaries (where particle concentration typically decreases). Doppler velocity values are generally associated with downward motion, and upward motion can be identified above 7$8 \mathrm{~km}$. Display $\mathrm{C}$ presents terminal velocity estimated after the $\mathrm{Vt}-\mathrm{Ze}$ approximation. Display D presents air vertical velocity, obtained by subtracting the terminal velocity from the Doppler velocity. Displays $\mathrm{E}$ to $\mathrm{H}$ present cloud properties associated with the particle model which has been identified as the most probable one for the daily dataset under consideration. These displays show time-height distributions of the ice particle number concentration, mass concentration, extinction coefficient, and effective radius. Measured ranges [19] for the mass concentration $\left(10^{-4}\right.$ to $\left.1 \mathrm{~g} / \mathrm{m} 3\right)$ and extinction coefficient $\left(10^{-5}\right.$ to $\left.10^{-2} \mathrm{~m}^{-1}\right)$ encompass almost entirely the RadOn estimates.

The impact of including the height in the approximation between terminal velocity and reflectivity can be appreciated by comparing Figures 1 and 2. Terminal velocity (display C) is now characterized by stronger downward motion near the cloud base (where larger particles are typically more frequent). Air vertical velocity (display D) now exhibits upward and downward motion patterns near cloud base and top. Such a result may indicate a better extraction of ice particle terminal velocity from the observed Doppler velocity field. Despite such differences, the Vt-Ze and Vt-Ze-H approaches allowed the identification of a same ice particle model among the (108) available choices into the RadOn first library. This possibility comes from the fact that the most probable model is searched by comparison, for a number of reflectivity bins, of terminal velocity estimates with respective theoretical values. The major difference between Figs. 1 and 2 involves number concentration estimates (display E). Despite the small differences affecting terminal velocities (display $\mathrm{C}$ ), the range of number concentration estimates enlarged dramatically: from a relatively narrow band around 100 particles per liter (Vt-Ze approach) to a range spanning from 1 to 1000 particles per liter, for an ice cloud cover thicker than $4 \mathrm{~km}$. Subtle changes affect the estimates of remaining microphysical properties, whose respective ranges increase a little. The vertical variability of number concentration obtained in Figure 2 appears to be in much better agreement with that reported using radar-lidar methods in other studies [20] than that seen in Figure 1.

The Vt-Ze-H approach provides some degree of freedom in relating terminal velocity and radar reflectivity. The former approach (Vt-Ze) is statistically more robust because only two parameters must be determined from experimental values of Doppler velocities and reflectivity. These approaches can provide very similar distributions of averaged terminal velocities per reflectivity bin and, as verified for the 14 April 2003 dataset, can enable the identification of a same ice particle model as being the most probable one.

A more complete picture of ice clouds as seen by one Doppler cloud radar can be obtained firstly by applying the RadOn method to tens of daily datasets, and then averaging ice cloud properties estimates at each radar bin. This strategy allows a first insight about the method performance because mean vertical profiles can be associated with a hypothetical ice cloud cover. Clouds are present at distinct heights from a day to another, and only a subset of heights was retained for analysis. This subset corresponds to at least one valid observation, at least one third (33) of 98 daily datasets which were successfully analyzed by both Vt-Ze and Vt-Ze-H approaches. In summary, $2.5 \mathrm{E}+6$ observations distributed between 1.836 and $9.756 \mathrm{~km}$ are taken into account.

Figure 3 presents the climatology of the ice cloud properties as derived from this systematic use of RadOn. For reference, mean air temperatures were about 261, 249, 236, and $222 \mathrm{~K}$ at heights of 4, 6, 8, and $10 \mathrm{~km}$ respectively. Displays A and B present extreme and averaged values of radar reflectivity and Doppler velocity. Ice cloud particle size and concentration strongly vary in time and space, allowing wide ranges for radar reflectivity and Doppler velocity. The latter are affected by air 
vertical motion too. The mean vertical profile of Doppler velocity indicates downward motions, which is consistent with the systematic downward contribution of the terminal fall velocities. Display C repeats such mean profile and presents ice particle terminal velocity as estimated through the Vt-Ze and $\mathrm{Vt}-\mathrm{Ze}-\mathrm{H}$ approaches. The expanded scale in this display turns evident that the magnitude of the mean Doppler velocity monotonically decreases above $6 \mathrm{~km}$. On average and with respect to the Vt-Ze approach, terminal velocity estimates after the Vt-Ze-H approach are closer from the mean Doppler velocity profile (display C) and hence produce weaker air vertical velocity estimates (display D). Because the search of the most probable ice model requires that the mean air vertical motion vanishes with respect to the mean ice particle fall speed field, the Vt-Ze-H approach represents an improvement to the RadOn method.

Ice particle terminal velocity and maximum dimension have been related both experimentally and theoretically $[15,21]$ : in general, the former increase with the latter. Terminal velocity mean profile after the Vt-Ze-H approach becomes weaker above $6 \mathrm{~km}$ (display C), and this can be translated as a reduction in particle maximum dimension with height. Effective radius mean profile presents such a tendency (display $\mathrm{H}$ ); nevertheless, it is not straightforward to associate these two microphysical properties because the influence of particle shape and size distribution [22, 23]. RadOn's effective radius estimates are proportional to the ratio of mass concentration to extinction coefficient, hence the $\mathrm{Vt}-\mathrm{Ze}$ and $\mathrm{Vt}-\mathrm{Ze}-\mathrm{H}$ approaches can allow different mean profiles for the latter properties (displays $\mathrm{F}$ and $G$ ) but similar mean profiles for the former (display H). Finally, these two approaches provided very distinct number concentration mean profiles (display E).

Heymsfield and McFarquhar [19] have established a three-layer conceptual model for in-situ generated cirrus clouds, consistent with earlier observations of ice development in cirrus convective elements or generating cells. According to that model: 1) the nucleation layer is the uppermost part of the cloud, composed of small ice crystals, where the relative humidity exceeds the value required for ice initiation, and ice production occurs; 2) the growth layer is composed of pristine ice crystal shapes, where ice-super-saturation sustains crystal growth and ice aggregates; and 3) the sublimation layer is composed of rounded crystals of nondescript shape, where ice sub-saturation causes crystals to sublimate and eventually disappear. Moreover, one or two of these layers can be absent if ice cloud cover is developing or decaying.

Our results are consistent with such a conceptual model. Mass concentration mean profiles (Figure 3, display G) from the RadOn method agree in the sense that both the Vt-Ze and Vt-Ze-H approaches provide crystals growth above $4-5 \mathrm{~km}$ and crystal sublimation below. Results from these approaches differ above $7-8 \mathrm{~km}$, where terminal velocity and number concentration estimates differ also (displays $\mathrm{C}$ and $\mathrm{E}$ ). Below $4 \mathrm{~km}$, number and mass concentration mean profiles present subtle variations as a possible result of averaging out distinct atmospheric conditions. The latter can evolve rapidly, as shown for instance between 11 and 13 UTC in displays E and F of Figure 2.

\section{Summary and Future Research}

We describe a main improvement to a method for estimating microphysical properties of ice clouds from observations conducted with the help of one Doppler cloud radar. The application of the method starts in approximating the terminal velocity $\mathrm{Vt}$ as a function of the radar reflectivity Ze. The present version of the method includes the influence of height $\mathrm{H}$ in that approximation.

The impact of including the height as an independent variable was evaluated. On statistical basis (98 daily datasets), terminal velocity estimates become weaker with height between 6 and $10 \mathrm{~km}$ (roughly 249 and $222 \mathrm{~K}$ ), indicating gradually smaller particles. Number concentration estimates now vary more appreciably above $4 \mathrm{~km}$ (roughly $261 \mathrm{~K}$ ). Both Vt-Ze and Vt-Ze-H approaches indicate the occurrence of a crystal growth layer, in accordance with a conceptual model established from in-situ ice cloud observations. We had emphasized the consistency of ice particle properties as estimated by the RadOn method. Their accuracy remains to be evaluated. Firstly, ice particles' optical thickness and mass content can be compared with similar provided by other methods, for a same dataset. Secondly, 
the evaluation of RadOn can employ a really independent measuring system, like in-situ airborne observations conducted right above the ground-based Doppler cloud radar under consideration. Lastly, a more effective co-location with nearby in-situ instrumentation can be achieved by involving the Doppler cloud radar RASTA in its airborne version: this has been implemented during a few research aircraft missions and the corresponding observations are under careful analysis.

The early implementation of the RadOn method has contributed to the evaluation of selected atmospheric models [17]. Its present version can be also applied to additional datasets to those considered in the CloudNet project. Good candidates for such an exercise are the world-wide sites operated in the framework of the Atmospheric Radiation Measurement program [4].

\section{Acknowledgements}

Authors warmly thank the LATMOS (formerly, CETP) engineers and technicians that have developed and operated the Doppler cloud radar RASTA. This study was performed with the financial support of the Centre National d'Etudes Spatiales (CNES) and INSU.

\section{References}

[1] G. L. Stephens, D. G. Vane, R. J. Boain, G. G. Mace, K. Sassen, Z. Wang, A. J. Illingworth, E. J. O'Connor, W. B. Rossow, S. L. Durden, S. D. Miller, R. T. Austin, A. Benedetti, C. Mitrescu, the CloudSat Science Team, The CloudSat mission and the A-train: A new dimension of space-based observations of clouds and precipitation, Bull. Amer. Meteor. Soc. 83 (2002) 1771-1790.

[2] D. R. Dowling, L. F. Radke, A summary of the physical properties of cirrus clouds, J. Appl. Meteor. 29 (1990) 970-978.

[3] M. Haeffelin, L. Barthes, O. Bock, C. Boitel, S. Bony, D. Bouniol, H. Chepfer, M. Chiriaco, J. Cuesta, J. Delanoe, P. Drobinski, J.-L. Dufresne, C. Flamant, M. Grall, A. Hodzic, F. Hourdin, F. Lapouge, Y. Lemaitre, A. Mathieu, Y. Morille, C. Naud, V. Noel, B. O'Hirok, J. Pelon, C. Pietras, A. Protat, B. Romand, G. Scialom, R. Vautard, SIRTA: A ground-based atmospheric observatory for cloud and aerosol research, Annales Geophysicae 23 (2005) 253-275.

[4] G. M. Stokes, S. E. Schwartz, The Atmospheric Radiation Measurement (ARM) Program: Programmatic background and design of the cloud and radiation test bed, Bull. Amer. Meteor. Soc. 75 (1994) 1201-1221.

[5] K. Sassen, J. M. Comstock, Z. Wang, G. G. Mace, Cloud and aerosol research capabilities at FARS: The Facility for Atmospheric Remote Sensing, Bull. Amer. Meteor. Soc. 82 (2001) 1119-1138.

[6] K. Sassen, G. G. Mace, Ground-based remote sensing of cirrus clouds, in: D. K. Lynch, K. Sassen, D. O'C. Starr, G. L. Stephens (Eds.), Cirrus, Oxford University Press, 2002, pp.168-196.

[7] H. Russchenberg, L. Spek, D. Moisseev, C. Utal, Y. Dufournet, C. Venkatachalan, On the use of spectral polarimetry to observe ice cloud microphysics with radar, in: S. Michaelides (Ed.), Precipitation: Advances in Measurement, Estimation, and Prediction, Springer Berlin Heidelberg, 2008, pp.285-312.

[8] J. M. Comstock, T. P. Ackerman, G. G. Mace, Ground-based lidar and radar remote sensing of tropical cirrus clouds at Nauru Island: Cloud statistics and radiative impacts, J. Geophys. Res. 107 (2002) D4714.

[9] Y. Yoshida, S. Asano, K. Iwanami, Retrieval of microphysical properties of water, ice, and mixedphase clouds using a triple-wavelength radar and microwave radiometer, J. Meteor. Soc. Japan 84 (2006) 1005-1031. 
[10] J. Delanoë, R. J. Hogan, A variational scheme for retrieving ice cloud properties from combined radar, lidar, and infrared radiometer, J. Geophys. Res. 113 (2008) D07204.

[11] J. Delanoë, "Modèle Inverse et Algorithmique pour exploiter la Synergie Radar-Lidar dans les Missions en tandem CLOUDSAT et CALIPSO ou dans la Mission EARTH-CARE", Thèse de Docteur de l'Université de Versailles Saint-Quentin-en-Yvelines soutenue le 16 décembre 2005.

[12] J. Delanoë, A. Protat, J. Testud, D. Bouniol, A. J. Heymsfield, A. Bansemer, P. R. A. Brown, and R. M. Forbes, Statistical properties of the normalized ice particle size distribution, J. Geophys. Res. 110 (2005) D10201.

[13] J. Delanoë, A. Protat, D. Bouniol, A. Heymsfield, A. Bansemer, P. Brown, The characterization of ice clouds properties from Doppler radar measurements, J. Appl. Meteor. Climatol. 46 (2007) 16821698 .

[14] H. P. Bohm, A general equation for the terminal fall speed of solid hydrometeors, J. Atmos. Sci. 46 (1989) 2419-2427.

[15] D. L. Mitchell, Use of mass- and area-dimensional power-laws for determining precipitation particle terminal velocities, J. Atmos. Sci. 53 (1996) 1710-1723.

[16] A. Protat, J. Pelon, N. Grand, P. Delville, P. Laborie, J.-P. Vinson, D. Bouniol, D. Bruneau, H. Chepfer, J. Delanoe, M. Haeffelin, V. Noel, and C. Tinel, Le projet RALI: Combinaison d'un radar et d'un lidar pour l'étude des nuages faiblement précipitants, La Météorologie 47 (2004) 23-33.

[17] A. J. Illingworth, R. J. Hogan, E. J. O’Connor, D. Bouniol, M. E. Brooks, J. Delanoe, D. P. Donovan, J. D. Eastment, N. Gaussiat, J. W. F. Goddard, M. Haeffelin, H. Klein Baltink, O. A. Krasnov, J. Pelon, J.-M. Piriou, A. Protat, H. W. J. Russchenberg, A. Seifert, A. M. Tompkins, G.-J. van Zadelhoff, F. Vinit, U. Willen, D. R. Wilson, C. L. Wrench, CLOUDNET: Continuous evaluation of cloud profiles in seven operational models using ground-based observations, Bull. Amer. Meteor. Soc. 88 (2007) 883-898.

[18] R. J. Hogan, E. J. O'Connor, "Facilitating cloud radar and lidar algorithms: The Cloudnet instrument synergy / target categorization product", Department of Meteorology, Reading University (available online at http://www.cloud-net.org/data/products/categorize.html), 2004.

[19] A. J. Heymsfield, G. M. McFarquhar, Mid-latitude and tropical cirrus, in: D. K. Lynch, K. Sassen, D. O'C. Starr, G. L. Stephens (Eds.), Cirrus, Oxford University Press, 2002, pp.79-101.

[20] A. Protat, J. Delanoë, A. Plana-Fattori, P. T. May, E. O'Connor, The statistical properties of tropical ice clouds generated by the West-African and Australian monsoons from ground-based radarlidar observations, Quarterly Journal of the Royal Meteorological Society (2009) (in press).

[21] J. D. Locatelli, P. V. Hobbs, Fall speeds and masses of solid precipitation particles, J. Geophys. Res. 79 (1974) 2185-2197.

[22] G. M. McFarquhar, A. J. Heymsfield, The definition and significance of an effective radius for ice clouds, J. Atmos. Sci. 55 (1998) 2039-2052.

[23] K. Wyser, The effective radius in ice clouds, J. Climate 11 (1998) 1793-1802. 

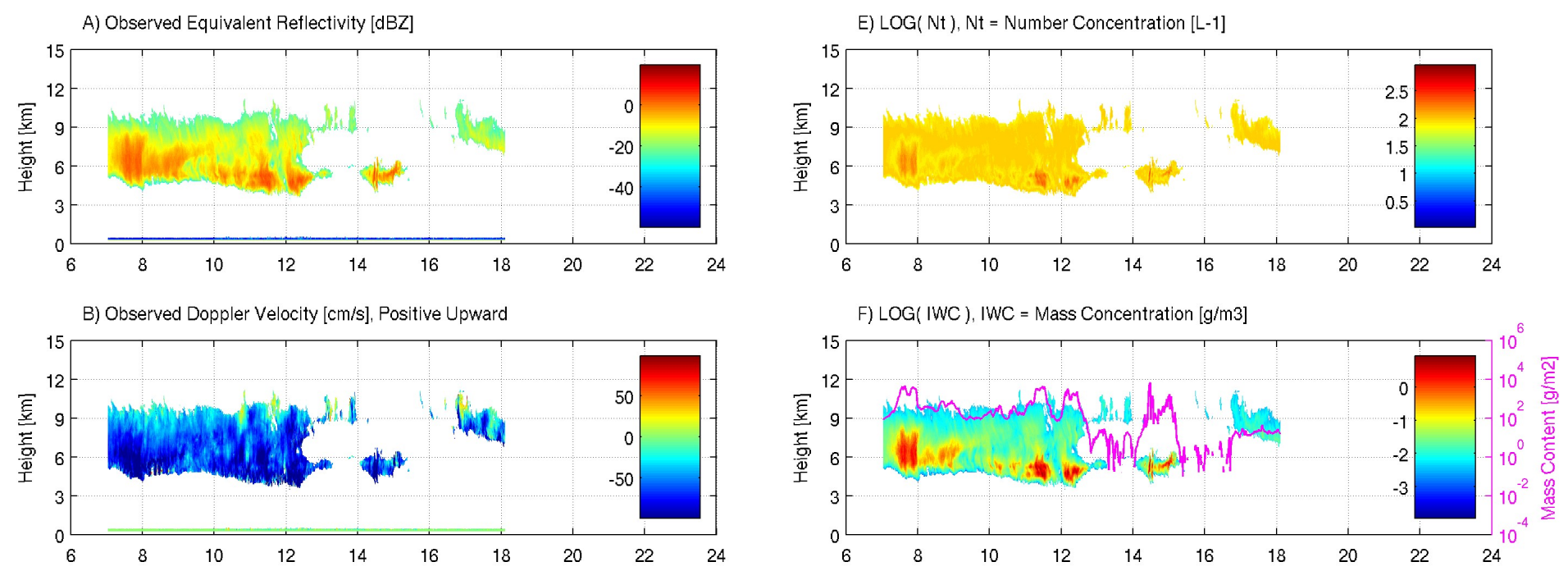

C) Ice Particle Terminal Velocity [cm/s], Positive Upward
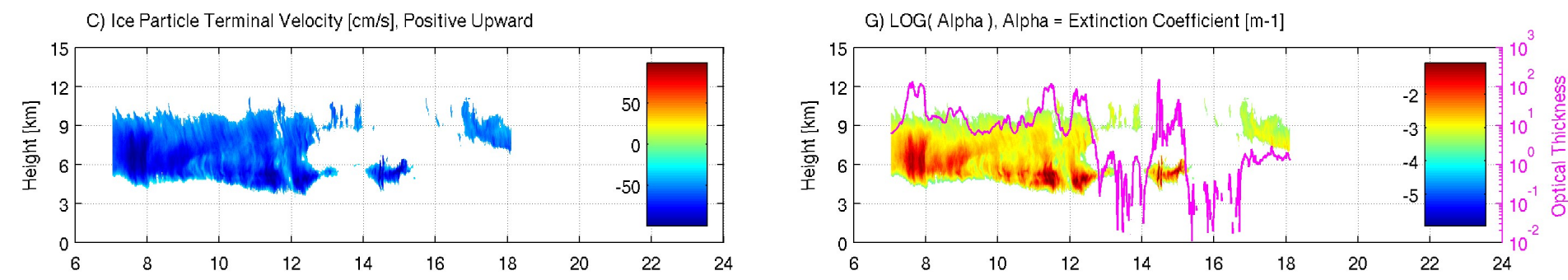

D) Air Vertical Velocity [cm/s], Positive Upward
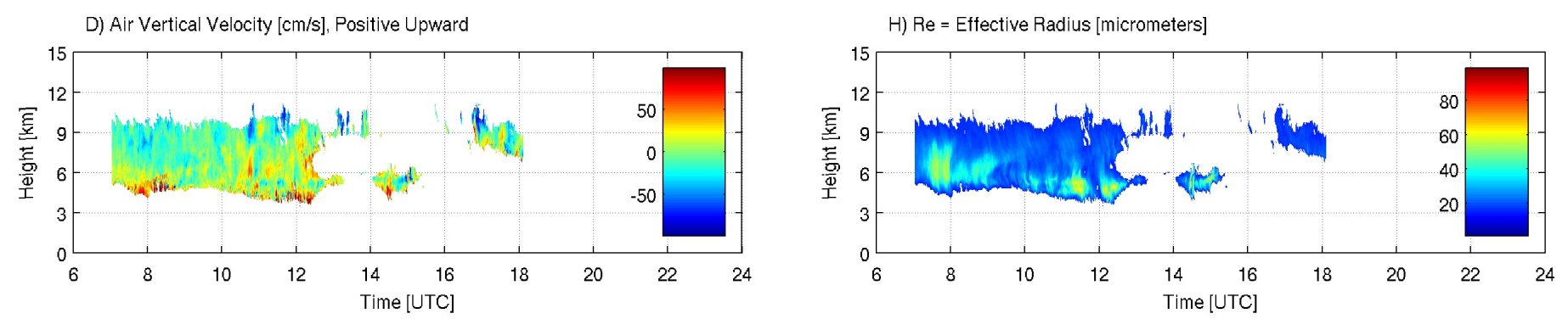

Fig. 1. Time versus height distribution of radar reflectivity (A) and Doppler velocity (B) observed on 14 April 2003 at Palaiseau, and ice particle terminal velocity estimated through the Vt-Ze approach (C). Remaining displays present estimates of air vertical velocity (D) and ice particles' number concentration (E), mass concentration (F), extinction coefficient (G), and effective radius $(H)$. Time series of ice mass content and optical thickness are also presented (scales on the right). 


\section{RASTA - SIRTA - 20030414 - Vt-Ze-H approach}
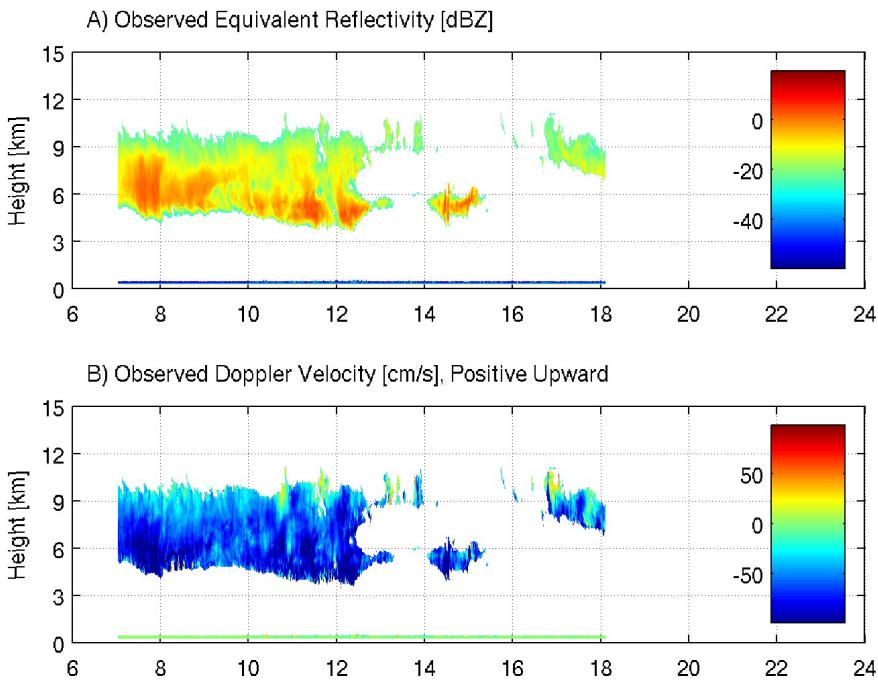

C) Ice Particle Terminal Velocity [cm/s], Positive Upward
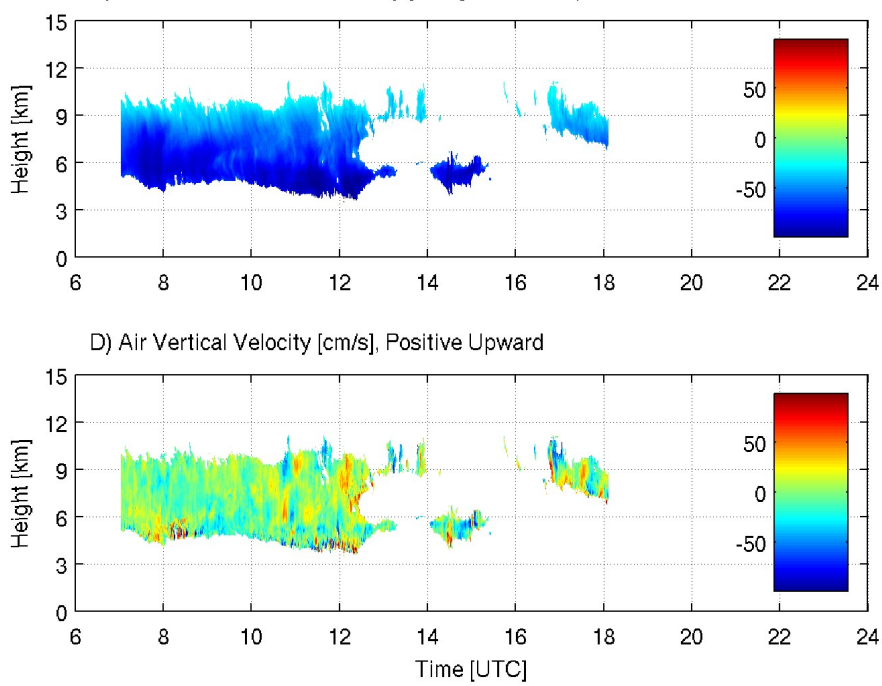

E) $L O G(N t), N t=$ Number Concentration [L-1]
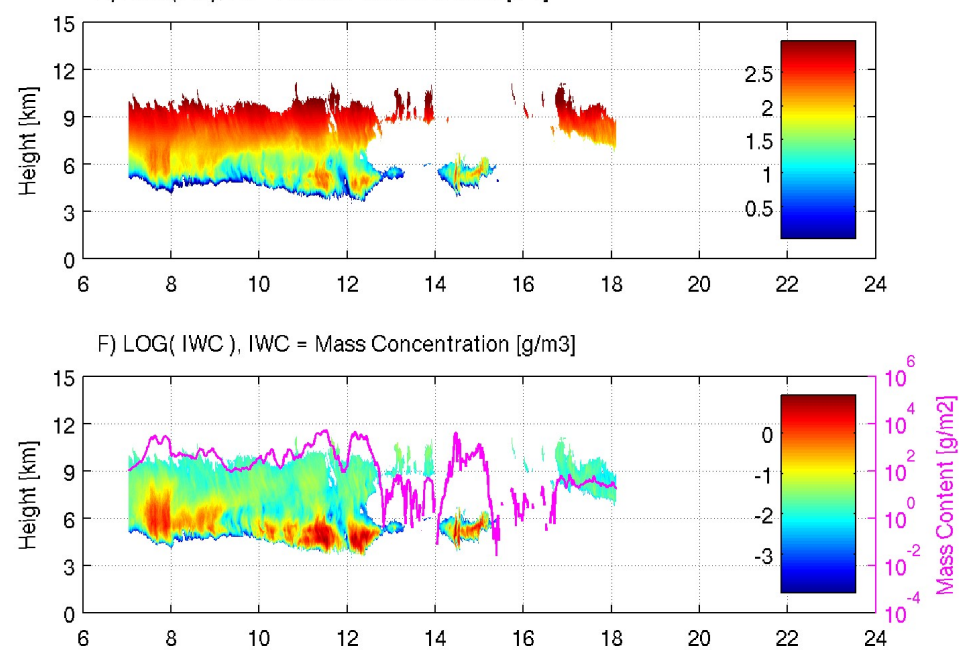

G) LOG(Alpha ), Alpha $=$ Extinction Coefficient [m-1]
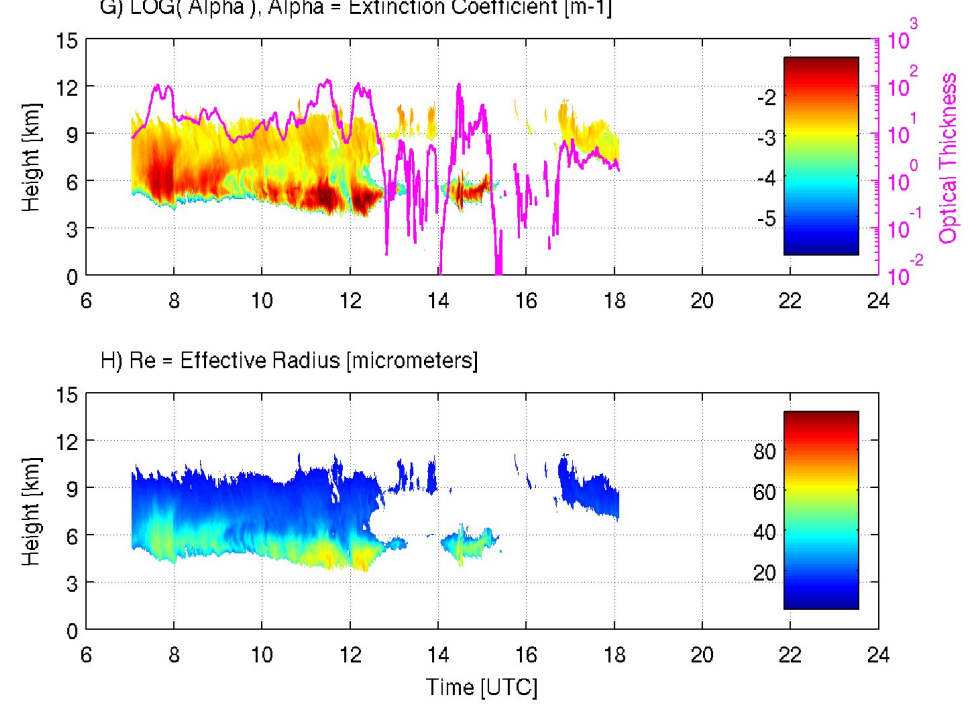

Fig. 2. As in Fig. 1 except for terminal velocities which were estimated through the Vt-Ze-H approach. 
A)

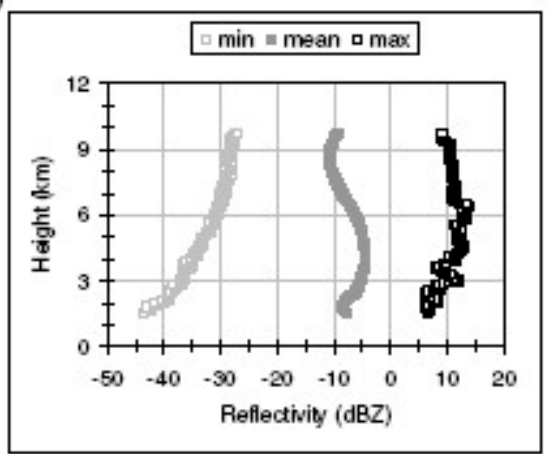

B)

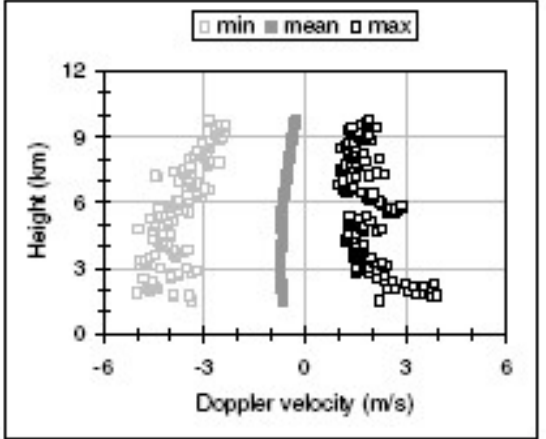

C)

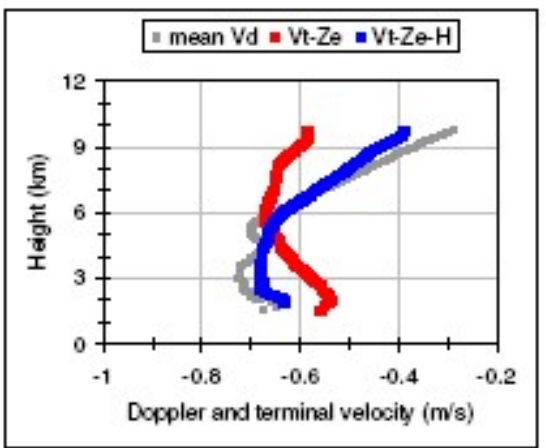

D)

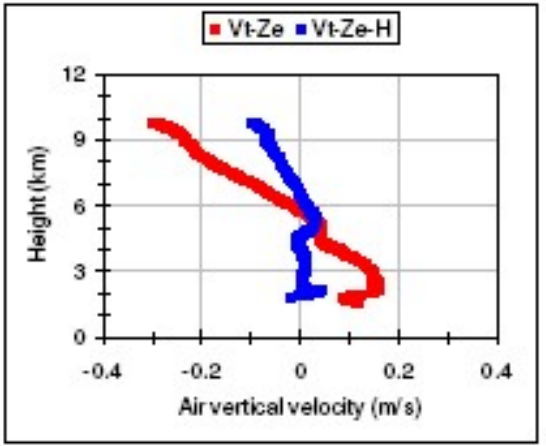

E)

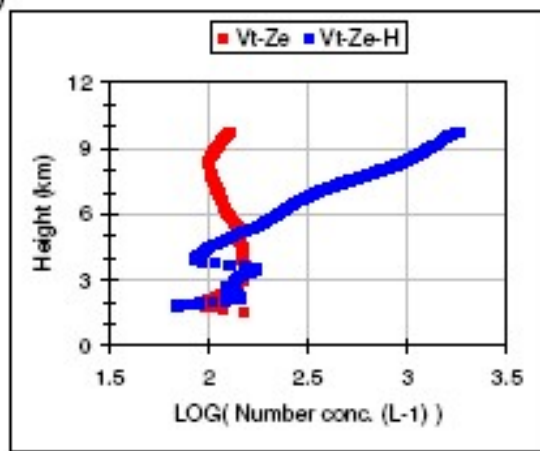

F)

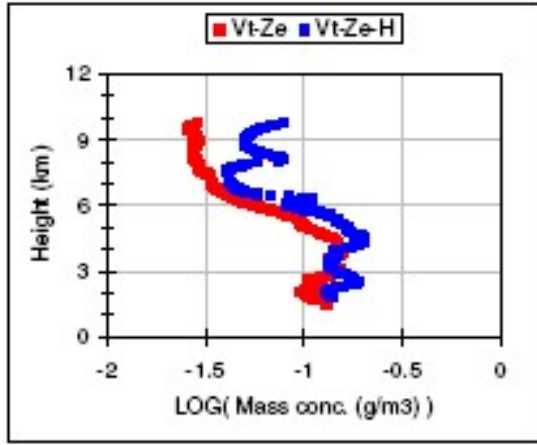

G)

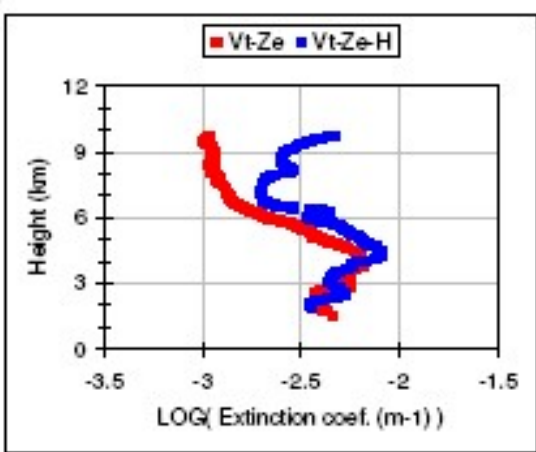

H)

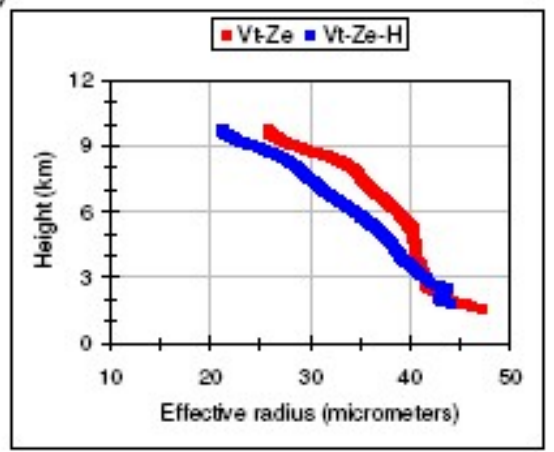

Fig. 3. Averaged vertical distributions of radar reflectivity (A) and Doppler velocity (B and C) from observations, and of estimated air vertical velocity (D), and ice particles' terminal velocity (C), number concentration $(\mathrm{E})$, mass concentration $(\mathrm{F})$, extinction coefficient $(\mathrm{G})$ and effective radius $(\mathrm{H})$ from the application of $\mathrm{Vt}-\mathrm{Ze}$ and $\mathrm{Vt}-\mathrm{Ze}-\mathrm{H}$ approaches. Minimum and maximum values of reflectivity and Doppler velocity are also shown. 